\title{
Identification of COX Inhibitors in the Hexane Extract of Japanese Horse Chestnut (Aesculus turbinata) Seeds
}

\author{
Itaru SATO ${ }^{1)}$, Hisayoshi KOFUJITA ${ }^{2)}$ and Shuji TSUDA ${ }^{1)}$ \\ ${ }^{1)}$ Laboratories of Veterinary Public Health and ${ }^{2)}$ Forest Product Chemistry, Faculty of Agriculture, Iwate University, 3-18-8 Ueda, \\ Morioka 020-8550, Japan
}

(Received 21 November 2006/Accepted 13 March 2007)

\begin{abstract}
Japanese horse chestnut (Aesculus turbinata) seed extract inhibits the activity of cyclooxygenase (COX), but its active constituents have not been identified. In the present study, COX inhibitors were isolated from the hexane extract of this seed by means of 4 steps of liquid chromatography and were identified by gas chromatography/mass spectrometry and nuclear magnetic resonance. The COX inhibitors in the extract of Japanese horse chestnut seeds were identified as linoleic acid, linolenic acid, and oleic acid. Their efficacies were in the following order: linolenic acid = linoleic acid > oleic acid. These active constituents are $\mathrm{C} 18$ unsaturated fatty acids; stearic acid, a C18 saturated fatty acid, had no activity. Linolenic acid and linoleic acid had high selectivity toward COX-2 (selectivity index $=10$ ), whereas oleic acid had no selectivity. Considering the efficacy and yield of each fatty acid, linoleic acid may be the principal COX inhibitor in this seed.
\end{abstract}

KEY WORDS: cyclooxygenase, inhibitor, Japanese horse chestnut, linoleic acid, linolenic acid.

Japanese horse chestnut (Aesculus turbinata) is a deciduous tree familiar in Japan for its big brown seeds. The seed is edible, and dryed ones contain $75.8 \%$ carbohydrate, $5.5 \%$ protein, and $4.5 \%$ lipid [6]. Its extract in combination with spirits has been utilized as a folk medicine for treatment of bruises and sprains in some regions of Japan. However, there are few pharmacological studies on the effectiveness and mechanism of this seed. We have recently reported that the extract of this seed has antioxidative and antigenotoxic effects in vitro [10] and antiinflammatory effects in vivo [9]. The extract inhibited cyclooxygenase (COX) activity, but had no effect on lipoxygenase and phospholipase $A_{2}$ [9]. COX produces inflammable chemical mediators from arachidonic acid, and inhibition of COX is the major mechanism of nonsteroidal antiinflammatory drugs (NSAIDs). Therefore, the antiinflammatory effect of Japanese horse chestnut seed must be caused, at least partly, by inhibition of COX.

There are two isoforms of COX; COX-1 is constitutively expressed in many tissues, while COX-2 is induced in inflamed tissues. COX-1 bears the basal production of cytoprotective PGs in gastric mucosa, and inhibition of COX-1 may cause gastric ulceration. Therefore, selectivity toward COX-2 is an important property of antiinflammatory drugs. Japanese horse chestnut seed extract inhibits COX-2 more strongly than COX-1 (9). This suggests that the seed contains COX-2 selective inhibitors.

Many studies have been conducted on the effect of naturally occurring chemicals and botanical resources on COX activity and COX-2 gene expression. Several natural compounds have been identified as COX inhibitors, including

\footnotetext{
* Correspondence to: Sato, I., Laboratory of Veterinary Public Health, Faculty of Agriculture, Iwate University, 3-18-8 Ueda, Morioka 020-8550, Japan.

e-mail: satoital@iwate-u.ac.jp
}

ajoene from allium, cyanidin from cherries, and myricetin3-O- $\beta$-D-glucuronide from Epilobium angustifolium [5]. However, the active constituents that inhibit COX have not been identified in Japanese horse chestnut seeds. In the present study, therefore, we separated COX inhibitors from the hexane extract of Japanese horse chestnut seeds and identified them by gas chromatography/mass spectrometry (GC/MS) and nuclear magnetic resonance (NMR).

\section{MATERIALS AND METHODS}

Japanese horse chestnut seed extract: Mature Japanese horse chestnut seeds were gathered from trees along a street in Morioka City. They were then washed with tap water and dried in the sun for several days. The shelled seeds were sliced and soaked in 4 volumes of hexane for 2 weeks at room temperature. The extract was filtered with filter paper (GS-25, Advantec Toyo, Tokyo, Japan) and concentrated with a rotary evaporator at $35^{\circ} \mathrm{C}$.

Isolation of COX inhibitors: COX inhibitors in the crude extract were separated and purified by 3 steps of low pressure liquid chromatography (LPLC) and 1 step of high pressure liquid chromatography (HPLC). The conditions are shown in Table 1. Each fraction of the eluate was examined for inhibitory effect on $\mathrm{COX}$, and then active fractions were applied to the next step. COX-inhibiting efficacy was determined by means of an assay kit (Cayman Chemical, Ann Arbor MI, U.S.A.) according to the manual included with the kit. The kit contained both COX-1 and COX-2 enzymes, so the effects on these two isozymes could be determined separately and specifically.

Identification of $\mathrm{COX}$ inhibitors: The separated active fractions were assayed by GC/MS to confirm their purity and to identify the COX inhibitors. The conditions of GC/ MS are shown below. 
Table 1. Conditions of chromatography

\begin{tabular}{|c|c|c|c|c|}
\hline & Step 1 (LPLC) & Step 2 (LPLC) & Step 3 (LPLC) & Step 4 (HPLC) \\
\hline \multirow[t]{2}{*}{ Column } & $\begin{array}{l}\text { Silicagel C300 } \\
\text { (Wako) }\end{array}$ & Sephadex LH20 & Sephadex LH20 & Inertsil ODS-3 \\
\hline & $\begin{array}{l}\text { (Wako) } \\
2.0 \times 30 \mathrm{~cm}\end{array}$ & $\begin{array}{l}\text { (Pharmacia) } \\
3.5 \times 50 \mathrm{~cm}\end{array}$ & $\begin{array}{l}\text { (Pharmacia) } \\
3.5 \times 50 \mathrm{~cm}\end{array}$ & $\begin{array}{l}\text { (GL Science) } \\
7.6 \times 250 \mathrm{~mm}\end{array}$ \\
\hline Monitor & - & - & - & UV (210 nm) \\
\hline Eluent & $\begin{array}{l}\text { Hexane-ether }(9: 1,8: 2 \text {, } \\
7: 3,7: 3,6: 4,5: 5), \text { ether, } \\
\text { ethanol-ether }(5: 5) \text {, } \\
80 \mathrm{~m} l \text { each }\end{array}$ & $\begin{array}{l}\text { Hexane-chloroform } \\
(2: 8)\end{array}$ & Methanol & $\begin{array}{l}\text { Acetonitrile-water } \\
(9: 1)\end{array}$ \\
\hline Flow rate & Natural dropping & Natural dropping & Natural dropping & $4 \mathrm{ml} / \mathrm{min}$ \\
\hline Sample vol. ${ }^{\text {a) }}$ & $3 \mathrm{ml}$ & $8 \mathrm{ml}$ & $8 \mathrm{ml}$ & $25 \mu l$ \\
\hline Fraction vol. & $80 \mathrm{ml} /$ fraction & $50 \mathrm{~m} l /$ fraction & $10 \mathrm{~m} / /$ fraction & Inconstant ${ }^{\mathrm{b})}$ \\
\hline $\begin{array}{r}\text { Concentration } \\
\text { method }\end{array}$ & $\begin{array}{l}\text { Rotary evaporator } \\
\left(35^{\circ} \mathrm{C}\right)\end{array}$ & $\begin{array}{l}\text { Rotary evaporator } \\
\left(35^{\circ} \mathrm{C}\right)\end{array}$ & $\begin{array}{l}\text { Centrifugal } \\
\text { evaporator }\end{array}$ & $\begin{array}{l}\text { Rotary evaporator } \\
\left(35^{\circ} \mathrm{C}\right) \text { and freeze-drier }\end{array}$ \\
\hline
\end{tabular}

a) Samples were diluted appropriately with eluent before application.

b) The eluate was collected in accordance with the chromatogram.

Table 2. Results of the first chromatography

\begin{tabular}{llrlrr}
\hline Fraction & Eluent & Yield & Appearance & COX-1 $^{\text {a) }}$ & COX-2 $^{\text {a) }}$ \\
\hline No.1 & Hexane:Ether=9:1 & $0 \mathrm{~m} l$ & & & \\
No.2 & Hexane:Ether=8:2 & $40 \mathrm{~m} l$ & Yellow & $122.8 \%$ & $70.3 \%$ \\
No.3 & Hexane:Ether=7:3 & $10 \mathrm{~m} l$ & Light yellow $^{\text {b) }}$ & $19.9 \%$ & $8.9 \%$ \\
No.4 & Hexane:Ether=6:4 & $1.5 \mathrm{~m} l$ & Light orange $^{\text {c }}$ & $24.0 \%$ & $14.8 \%$ \\
No.5 & Hexane:Ether=5:5 & $2.5 \mathrm{~m} l$ & Orange $^{\text {c) }}$ & $113.6 \%$ & $41.3 \%$ \\
No.6 & Ether & $1.2 \mathrm{~m} l$ & Deep orange & $100.9 \%$ & $44.6 \%$ \\
No.7 & Ethanol:Ether=5:5 & $0.5 \mathrm{~m} l$ & Deep orange, pasty & $6.1 \%$ & $4.3 \%$ \\
\hline
\end{tabular}

a) Activity is expressed as a percentage of the control.

b) Whole or c) partial coagulation occurred in a refrigerator.

Apparatus: GC, 5890 II; MSD, 5972; Injector, 6890

(Hewlett Packard).

Column: HP-5MS $(0.25 \mathrm{~mm} \times 30 \mathrm{~m}, \mathrm{~J} \& \mathrm{~W})$.

Temperature: Injection, $250^{\circ} \mathrm{C}$; Column, $70^{\circ} \mathrm{C}(2 \mathrm{~min})-$ $10^{\circ} \mathrm{C} / \mathrm{min}-280^{\circ} \mathrm{C}(5 \mathrm{~min})$.

Carrier gas: He (>99.99995\%).

Sample volume: $1 \mu l(1 \mathrm{mg} / \mathrm{m} l$ in hexane $)$.

The mass spectrum of each peak on chromatograms was automatically compared with reference spectra in a library (NIST/EPA/NIH-75K Mass Spectral Database) to identify the COX inhibitor in the fraction. When the fraction was pure, further identification was carried out by ${ }^{13} \mathrm{C}-\mathrm{NMR}$ (JNM-AL400, JEOL, Tokyo, Japan) using standard conditions. The raw data for NMR was converted to chemical shift values and compared with the reference values of the material identified by GC/MS (The Aldrich Library of ${ }^{13} \mathrm{C}$ and ${ }^{1} \mathrm{H}$ NMR Spectra).

After the COX inhibitors were identified by GC/MS and NMR, the same chemicals as those identified were purchased as standards, and their efficacies were examined in the same manner as described above. Statistical analysis of the efficacies was conducted by Welch's $t$-test, and $\mathrm{p}<0.05$ was considered to be significant.

\section{RESULTS}

Table 2 shows the results of step 1 . The activity of COX-
Table 3. Results of the second chromatography

\begin{tabular}{lclc}
\hline Fraction & Yield & Appearance & COX-2 \\
\hline No.1 & $1.84 \mathrm{~g}$ & Orange-yellow, liquid & $112.2 \%$ \\
No.2 & $0.02 \mathrm{~g}$ & Yellow, solid & $138.8 \%$ \\
No.3 & $0.46 \mathrm{~g}$ & Transparent, jelly & $97.8 \%$ \\
No.4 & $2.94 \mathrm{~g}$ & Transparent, liquid & $21.6 \%$ \\
No.5 & $1.24 \mathrm{~g}$ & Transparent, liquid & $7.4 \%$ \\
No.6 & $0.99 \mathrm{~g}$ & Transparent, liquid & $4.2 \%$ \\
No.7 & $0.53 \mathrm{~g}$ & White, solid & $5.9 \%$ \\
No.8 & $0.27 \mathrm{~g}$ & White, solid & $7.9 \%$ \\
No.9 & $0.23 \mathrm{~g}$ & White, solid & $4.6 \%$ \\
No.10 & $0.17 \mathrm{~g}$ & Translucent white, solid & $3.4 \%$ \\
No.11 & $0.15 \mathrm{~g}$ & Transparent, solid & $3.2 \%$ \\
\hline
\end{tabular}

a) Activity is expressed as a percentage of the control.

1 was inhibited by fractions Nos. 3, 4, and 7. Although COX-2 activity was inhibited by all fractions, strong inhibition was observed for fractions Nos. 3, 4, and 7. Because the yield of No. 7 was too small for application to further examinations, fractions Nos. 3 and 4 were applied to the next step.

Table 3 shows the results of step 2 . In this step, only the effect on COX-2 was examined as a indicator of efficacy. Fractions Nos. 1, 2, and 3 had no inhibitory effects on COX2. Fraction No. 4 had the highest yield but its activity was lowest among the active fractions. Fractions No. 5 to 11 had high activities and sufficient yields. Thus, fractions No. 5 to 
Table 4. Results of the 4th chromatography

\begin{tabular}{lrlcc}
\hline Fraction & Yield & Appearance & COX-1 & COX-2 \\
\hline No.1 & $55 \mathrm{mg}$ & Light yellow, liquid & $2.4 \%$ & $1.7 \%$ \\
No.2 & Trace & Light yellow & - & - \\
No.3 & $573 \mathrm{mg}$ & Light yellow, liquid & $3.4 \%$ & $3.7 \%$ \\
No.4 & $1541 \mathrm{mg}$ & White, solid & $38.5 \%$ & $64.5 \%$ \\
\hline
\end{tabular}

a) Activity is expressed as a percentage of the control.

11 were applied to the next step.

Step 3 chromatography produced a single large peak, and further separation could not be achieved by this method. Thus, all of the fractions participating in the peak were applied to the next step without measuring the activity.

HPLC separated the sample into 3 large peaks with 1 small shoulder peak, so the eluate was divided into 4 fractions in accordance with the chromatogram. Table 4 shows the results of this step. Although all of the fractions but No. 2 had activity to inhibit both COX-1 and COX-2, fractions Nos. 1 and 3 had remarkable effects. The yield of fraction No. 2 (shoulder peak) was too small to determine its activity.

Fractions Nos. 1, 3, and 4 were assayed by GC/MS in order to verify their purity and, if possible, identify them. Fractions Nos. 1 and 3 formed a single peak on a chromatogram. Mass spectra of these peaks were compared with reference spectra, and they were identified as linolenic acid (No. 1) and linoleic acid (No. 3), respectively, with high reliability (data were omitted). Fraction No. 4 formed several peaks on a chromatogram; two of the peaks were identified as stearic acid and oleic acid via a spectral search. Because of their high purity, fractions Nos. 1 and 3 were applied to the NMR analysis, and the results indicated that the chemical shift values of fractions Nos. 1 and 3 corresponded to the reference values of linolenic acid and linoleic acid, respectively (data were omitted). Fraction No. 4 was not analyzed by NMR because of its impurity.

Fractions Nos. 1 and 3 were identified as linolenic acid and linoleic acid, respectively, and fraction No. 4 contained stearic acid and oleic acid. Therefore, these 4 fatty acids were examined for their efficacies, and the results are shown in Fig. 1. Linolenic acid and linoleic acid dose-dependently inhibited COX-1 and COX-2 activity, and almost complete inhibition was achieved at a concentration of $0.2 \mathrm{mg} / \mathrm{ml}$. Both fatty acids inhibited COX-2 more strongly than COX1. There were no significant differences in COX-inhibiting activity between linolenic acid and linoleic acid. As the $\mathrm{IC}_{50} \mathrm{~s}$ of these fatty acids were about $0.03 \mathrm{mg} / \mathrm{ml}(=0.1 \mathrm{mM})$ for COX-1 and $0.003 \mathrm{mg} / \mathrm{m} l(=0.01 \mathrm{mM})$ for COX-2, the selectivity index for COX-2 $\left(\mathrm{SI}=\left[\mathrm{IC}_{50}\right.\right.$ for COX-1] $/\left[\mathrm{IC}_{50}\right.$ for COX-2] ) was 10 . Oleic acid inhibited both isozymes comparably $\left(\mathrm{IC}_{50}=0.4 \mathrm{mg} / \mathrm{m} l\right)$, but its efficacy was lower than those of linolenic acid and linoleic acid. Stearic acid did not inhibit the activity of COX.

\section{DISCUSSION}

The major COX inhibitors in the hexane extract of Japanese horse chestnut seeds were identified as linolenic acid and linoleic acid by means of GC/MS and NMR. Oleic acid was also present in the extract and was confirmed to have COX-inhibiting activity. Ringbom et al. [8] reported that COX-1 and COX-2 activity was inhibited by eicosapentaenoic acid (EPA), docosahexaenoic acid (DHA), linolenic acid, and linoleic acid, but not by oleic acid, stearic acid, or other saturated fatty acids. Their results concerning oleic acid were different from ours. They may have only examined it up to a concentration of $0.14 \mathrm{mg} / \mathrm{m} l(0.5 \mathrm{mM})$, while we examined it at concentrations of up to $1 \mathrm{mg} / \mathrm{ml}$. Thus, we conclude that oleic acid has COX-inhibiting activity. The other findings of Ringbom et al. are consistent with the present study.
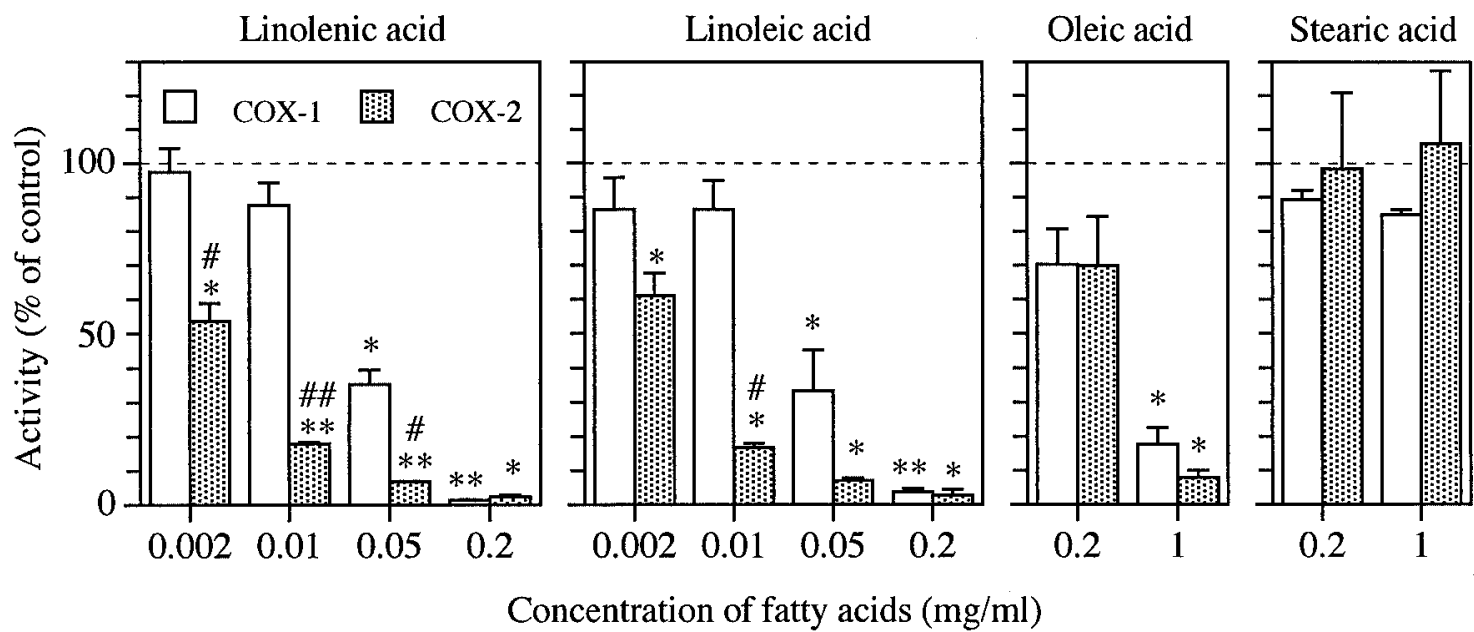

\section{Concentration of fatty acids $(\mathrm{mg} / \mathrm{ml})$}

Fig. 1. Inhibition of COX-1 and COX-2 activity by 4 kinds of $\mathrm{C} 18$ fatty acid. Values are expressed as means \pm SD of duplicated determinations. * and $* *$ : significant inhibition at $\mathrm{p}<0.05$ and $\mathrm{p}<0.01$, respectively. \# and \#\#: significant difference between COX-1 and COX-2 at $\mathrm{p}<0.05$ and $\mathrm{p}<0.01$, respectively. 
All of these active substances are C18 unsaturated fatty acids; oleic acid has 1 double bond $(18: 1, \omega-9)$, linoleic acid has 2 double bonds $(18: 2, \omega-6)$, and linolenic acid has 3 double bonds $(18: 3, \omega-3)$. On the other hand, stearic acid, a C18 saturated fatty acids, had no activity. These results suggest that "C18 fatty acids" and "unsaturated double bonds" are key configurations for inhibition of COX activity. On the other hand, commercially produced COX inhibitors have a six-membered ring and/or five-membered ring in their molecules. Some of them have a carboxyl group, but none of them have a double-bonded aliphatic hydrocarbon. Therefore, there are no structural similarities between commercial COX inhibitors and $\mathrm{C} 18$ unsaturated fatty acids. The COX reaction produces prostaglandins by converting arachidonic acid (20:4, $\omega-6)$. However, this enzyme can oxidize several other unsaturated fatty acids such as EPA (20:5, $\omega-3)$, linolenic acid, and linoleic acid [4,7]. This suggests that these unsaturated fatty acids compete with arachidonic acid as substrates for COX.

Although oleic acid had no selectivity, linolenic acid and linoleic acid had selectivity toward COX-2 (Fig. 1). This result is consistent with our previous study in which the crude extract of Japanese horse chestnut seeds inhibited COX-2 more strongly than COX-1 [9]. There are many NSAIDs that act as COX inhibitors, but not all of them have selectivity toward COX-2. Famous COX inhibitors, such as aspirin, indometacin, ibuprofen, and ketoprofen, have no selectivity toward COX-2. The COX-2 selectivities of linoleic acid and linolenic acid $(\mathrm{SI}=10)$ are comparable to commercial COX-2 inhibitors such as etodolac $(\mathrm{SI}=8)$ and mefenamic acid $(\mathrm{SI}=12)$ [1]. The $\mathrm{IC}_{50}$ of linoleic acid and linolenic acid for COX-2 $(10 \mu \mathrm{M})$ is comparable to ibuprofen $(9.9 \mu \mathrm{M})$ and lower than aspirin $(14 \mu \mathrm{M})$ and sulindac $(25 \mu \mathrm{M})$, although it is higher than several strong COX inhibitors, including mefenamic acid $(0.16 \mu \mathrm{M})$, indometacin $(0.37 \mu \mathrm{M})$, and ketoprofen $(0.88 \mu \mathrm{M})$ [1]. Therefore, linolenic acid and linoleic acid may be promising as antiinflammatory agents.

Linolenic acid had high activity but its yield from the extract was very low. Linoleic acid had high activity and its yield was 10 times that of linolenic acid. The activity of oleic acid was considerably lower than those of linolenic acid and linoleic acid. Therefore, linoleic acid is considered to be the principal COX inhibitor in the hexane extract of Japanese horse chestnut seeds. Linolenic acid and oleic acid also contribute to COX inhibition. In general, plant seeds contain unsaturated fatty acids such as linoleic acid and linolenic acid, but they exist in ester forms. This is the first report in which Japanese horse chestnut seeds were confirmed to contain extractable free fatty acids.

Japanese horse chestnut seeds also contain saponins, coumarins, and polyphenols $[2,10]$. We have already con- firmed that some kinds of saponins and coumarins have no effect on COX activity [9], but some polyphenolic compounds are known to have COX-inhibiting activity [3, 11, 12]. In the present study, we isolated COX inhibitors from hexane extract that did not contain hydrophilic constituents. Moreover, active constituents were not isolated from fraction No. 7 in the first chromatography because of its low yield. Therefore, Japanese horse chestnut seeds may contain other COX inhibitors besides C18 unsaturated fatty acids.

\section{REFERENCES}

1. Cryer, B. and Feldman, M. 1998. Cyclooxygenase-1 and cyclooxygenase-2 selectivity of widely used nonsteroidal antiinflammatory drugs. Am. J. Med. 104: 413-421.

2. Fujimaki, H. 1998. Tochinoki. pp. 230-234. In: Chiiki Seibutushigen Katsuyou Jiten, Noubunkyo, Tokyo (in Japanese).

3. Hong, J., Smith, T.J., Ho, C.T., August, D.A. and Yang, C.S. 2001. Effects of purified green and black tea polyphenols on cyclooxygenase- and lipoxygenase-dependent metabolism of arachidonic acid in human colon mucosa and colon tumor tissues. Biochem. Pharmacol. 62: 1175-1183.

4. Laneuville, O., Breuer, D.K., Xu, N., Huang, Z.H., Gage, D.A., Watson, J.T., Lagarde, M., DeWitt, D.L. and Smith, W.L. 1995. Fatty acid substrate specificities of human prostaglandinendoperoxide H synthase-1 and -2. J. Biol. Chem. 270: 19330 19336.

5. Perera, P., Ringbom, T., Huss, U., Vasänge, M. and Bohlin, L. 2001. Search for natural products which affect cyclooxygenase-2. pp. 435-472. In: Bioactive Compounds from Natural Sources (Tringali, C. ed.), Taylor \& Francis, London.

6. Resources Council, Science and Technology Agency. 1982. pp. 92-93. In: Nihon Shokuhin Hyojun Seibunhyo, 4th ed., Printing Bureau, Ministry of Finance.

7. Rieke, C.J., Mulichak, A.M., Garavito, R.M. and Smith, W.L. 1999. The role of arginine 120 of human prostaglandin endoperoxide $\mathrm{H}$ synthase- 2 in the interaction with fatty acid substrates and inhibitors. J. Biol. Chem. 274: 17109-17114.

8. Ringbom, T., Huss, U., Stenholm, A., Flock, S., Skattebol, L., Perera, P. and Bohlin, L. 2001. COX-2 inhibitory effects of naturally occurring and modified fatty acids. J. Nat. Prod. 64: 745-749.

9. Sato, I., Kofujita, H., Suzuki, T., Kobayashi, H. and Tsuda, S. 2006. Antiinflammatory effect of Japanese horse chestnut (Aesculus turbinata) seeds. J. Vet. Med. Sci. 68: 487-489.

10. Sato, I., Suzuki, T., Kobayashi, H. and Tsuda, S. 2005. Antioxidative and antigenotoxic effects of Japanese horse chestnut (Aesculus turbinata) seeds. J. Vet. Med. Sci. 67: 731-734.

11. Seeram, N.P., Cichewicz, R.H., Chandra, A. and Nair, M.G. 2003. Cyclooxygenase inhibitory and antioxidant coumpounds from crabapple fruits. J. Agric. Food Chem. 51: 1948-1951.

12. Seeram, N.P., Zhang, Y. and Nair, M.G. 2003. Inhibition of proliferation of human cancer cells and cyclooxygenase enzymes by anthocyanidins and catechins. Nutr. Cancer 46: 101-106. 